\title{
Automatic Translation of Arabic Classic Poetry; Case-Study of Google Translate
}

\author{
Dr. Mousab Alata Elseddig Adiel (Adiel, M.A)* \\ Assistant Professor of Translation, Imam Abdulrahman Bin Faisal University KSA
}

*Corresponding Author: Dr. Mousab Alata Elseddig Adiel (Adiel, M.A), Assistant Professor of Translation, Imam Abdulrahman Bin Faisal University KSA

\begin{abstract}
In this study the author followed the evidence-based approach to analyze the translation of google as machine translation (MT). The study sample includes quotes from Arabic poetry among classic poems. As an evidence the author provided the links of the translated quotes from Arabic into English according to the quotes' numbers in the part of the appendices. The author also meant to enter the mark (*) as an indication that the work was done by him. For further documentation to the evidences the author took screenshots for the translated quotes. The aim of the study is searching the gap between machine-based translation and human translation to be bridged by providing comments after analysis. This study can be considered as an applied study on Google Translate and as a contrastive study between human translation and machine-based translation from Arabic language into English language.
\end{abstract}

\section{INTRODUCTION}

Computer machine is available anywhere nowadays. People are seeking to computerize every work in the different fields of science and aspects of life, from the cashier of small business to running of big medical surgeries or designing of skyscrapers. For decades computerization or automation of works became the request of any institution or business for different purposes as boosting productivity, cost reduction, time saving, or even may be fidelity. Translation is not an exception or far from this. Electronically we see many computer applications or programs for translation. The most famous of them as free is Google Translate which will be investigated in this paper for the purpose of translating of Arab classic poetry as a literary cross-cultural genre. It is indeed that the ways in which technology may affect translation and its future have been the object of much scholarly works (e.g. Alonso and Vieira 2017; Baumgarten and Cornellà-Detrell 2017; Cronin 2013; Mitchell and Raley 2018; Moorkens 2017), but will this be applicable on an ancient language as Arabic language?. Will the computer memory change the scene and affect the future of Arab translators? Will Google Translate be able to translate an ancient culture and convey the emotions of the poets of that era overtaking all the cultural and social dimensions. The answers for these questions will be seen in the details and the conclusion of this case-study of Google Translate as an applied analytical study.

\section{COMPUTER-ASSisted Translation}

Translation memory software is a computer-assisted translation (CAT) tool designed to facilitate the process of translation (Maeve Olohan ,2011). TM allows translators to store source and target texts in such a way that source text sentences or sub-sentential segments will be recognized by the software if encountered again; the previously used translation can then be retrieved from that memory according to the programming of the software. As the translator works through a text, the software will identify those segments which are matches (exact or fuzzy) with segments in the memory; it can produce those previously used translation solutions while also storing the newly generated translations for future reuse. The main benefit of using TM software is that it eliminates repetitive work and helps to ensure consistency across texts or for teams of translators. There are usually productivity gains: if the translator has to translate only parts of a text, she/he can translate at a faster rate. There are also savings to be made for translation companies or agencies or clients, as TM tools allow companies to analyze source texts before they send them to translators, ascertaining the extent of matching and being able to budget for time and costs accordingly. 
It is useful to consider existing research on TM use by translators(ibid). Alongside some trainingoriented overviews of TM and other CAT tools (e.g., Austermühl 2001; Alcina 2008), several surveybased studies have tracked the uptake of TM by translators, examining various aspects of usage. For example, Dillon and Fraser (2006) and Fulford and Granell-Zafra (2005) established that nonadoption of TM had more to do with lack of awareness of the capabilities and functionalities of the software than active rejection of it. These surveys found that most translators trained themselves to use TM, but that was a time-consuming process and the effort involved in learning the software acted as a disincentive; however, those who used it regularly reported gains in productivity, consistency and quality (Fulford 2001; Fulford and Granell-Zafra 2005; Lagoudaki 2006)

Only a small number of scholars have set out to study aspects of how translators use TM(Maeve Olohan ,2011). Bowker (2005), for example, investigated the relationship between productivity, or speed of translating, and quality by comparing translators not working with a TM to those using a TM and those using a TM which contained errors. Elsewhere, Bowker (2007) examined the impact of TM on features of textuality, noting that processing the text in sentence units, as encouraged by TM, has a detrimental effect on textual cohesion. Bowker concluded that training is crucial if translators are to become critical users of TM. Kenny (1999) also called for research on how TM tools can change the task of the translator, observing, for example, that students implement time-saving tricks when working with TM, for example by not selecting target-text syntactic structures which would make those segments more difficult to reuse. O'Brien (2006) researched the cognitive loads of TM use, showing that cognitive loads were lightest when translators processed exact matches, but increased incrementally for fuzzy matches and unmatched segments. Also interested in translation processes, Alves and Liparini Campos (2009) found that under time pressure translators using TM were more inclined to use, unedited, the solutions proposed by the TM and to take decisions by first considering (external) support resources and then making judgements drawing on their own (internal) knowledge.

Translation scope of work is not limited to the cognitive and linguistic aspects only, but furthermore it has other social, cultural, and emotional dimensions. Machine-based translation could give us the lexical meaning and the equivalent words from the source language to the target language without the ability to reflect our emotions or tackle issues in their culture and sociological context. In this paper which runs a comparison between two types of translation, the case of Google Translate as TM and my own translation as human-based translation, I found that its urgently to review the approach of Pickering and other proponents and opponents scholars regarding human and non-human agency making use of the study published by Taylor and Francis as prepared by Maeve Olohan,2011 regarding translators and translation technology.

\section{The Model Of Human \& Non-Human AgenCy}

Translation studies are increasingly interested in the agency of translators and interpreters (e.g., Wolf and Fukari 2007; Milton and Bandia 2009; Kinnunen and Koskinen 2010); the translator is studied as an actor whose choices and behavior are motivated not just by linguistic or cognitive factors, but by social and ideological ones too. Translation scholars drawing on sociological models have tended to focus on translation or interpreting activities where social relevance is immediately obvious, such as interpreting for asylum seekers (e.g., Inghilleri 2007), translating or interpreting in situations of conflict (e.g., Baker 2006) or translating or interpreting for activist organizations (e.g., Boéri 2008). In these and other studies, human agency is the focus of attention, and little interest is shown in the action of the material or non-human. Many scholars in science and technology studies (STS), by contrast, seek to account, in various ways, for the range of components or agents - social, human, material, technical, conceptual - involved in constituting science and technology and for the interactions between these components or agents. Proceeding from the assumption that translation studies could benefit from a broader base of sociological influences and a consideration of the role of the material and the technical in translation practice, (Maeve Olohan ,2011) in her study about translators and translation technologyintroduced the model of human and non-human agency offered by the sociologist of science Andrew Pickering. In her opinion, Pickering's approach has been successfully applied to the study of the implementation of information systems in organizations and may therefore offer a productive conceptual approach to the study of translators and translation technology.

Pickering (e.g., 1993, 1995, 2008a, 2008b) sets out to develop a theory to account for scientific and technological innovations. He gives a prominent role to non-human - that is, material - agency, and 
sees science and technology as emerging like laundry which has been wrung through a mangle. The "mangle of practice" represents the dialectic of resistance and accommodation, which is brought to bear on scientific and technological advances. Resistance can be offered by any entity, including material objects; this can be seen particularly well in the course of those scientific experiments where apparatus and other material objects offer resistance to the smooth running of the experiment or to the gathering or analysis of relevant data. Accommodations are made by the scientist to overcome or avoid resistances, and Pickering calls the interplay of human and non-human agency as they interactively stabilize each other the "dance of agency". This process of mutual adjustment is also likened to the tuning of a car radio or engine. One of Pickering's examples (2008a) which illustrates this well is that of the Mississippi and its levees and weirs. A dance of agency is performed by the engineers and the river: the engineers try to control the river by raising levees and building weirs, while the river rises above the levees or tears away at the weirs' structure as it tries to flow its natural course.

The language services industry can be seen as the "surface of emergence" (a Foucauldian term appropriated by Pickering; 1995, 21) for the TM technology, that is to say, the industry provided the conditions for the development of TM and has, in turn, been reconfigured by that development.

Pickering's notions of human and non-human agency are often contrasted with those of Giddens (in his structuration theory, e.g., 1986) and Latour (in his actor-network theory, e.g., 2005). Proponents of Pickering's approach see some deficiencies in both Giddens's and Latour's ways of handling agency. In particular, structuration theory privileges human agency and does not accommodate material agency, while actor-network theory assumes a certain symmetry between human and non-human agency, not distinguishing between them (for an IS-related discussion, see Jones and Karsten 2008). By contrast, Pickering focuses more on the interplay between the two forms of agency, for which no symmetry is assumed. However, as Pickering acknowledges, the notion of material agency is not readily accepted by those who see intention as a core component of agency. Because he conceives of non-human agency as "material powers and performances" (2005a, 359) and does not attribute intention or will to material objects, Orlikowski $(2005,185)$ suggests that it would be more helpful to speak of "human agency" and "material performativity". Extending this to the study of translators and $\mathrm{TM}$, we might reformulate our focus as being the intertwining of human agency and technological performativity. Of course, numerous other scholars have addressed the question of (human and material) agency, and there are also approaches and models which seek to accommodate a greater degree of complexity. Rammert (2008), for example, in his model of distributed agency, offers a differentiation of human agency and technological action by their degree, as well as a typology of inter-agency between humans and technology. His aim is to produce a gradual model of agency with levels of causality, contingency and intentionality.

(Läubli, Samuel and Orrego-Carmona, David.2017), in their article "When Google Translate is Better Than Some Human Colleagues, Those People Are no Longer Colleagues." In Proceedings of the 39th Conference Translating and the Computer, 59-69.Reserach Gate) investigated translator groups on Facebook and LinkedIn and carried out a sentiment analysis of tweets mentioning MT. Their focus was mainly on whether opinions towards MT were positive, negative, or neutral, however. They provided awesome recommendations about the method of how translators could share to fill and bridge the gap between MT and human-based translation.

Cadwell, O'Brien, and Teixeira (2018) used focus groups to research the factors behind the adoption and non-adoption of MT at the European Commission and among in-house translators at a UK translation company.

In this paper, according to the analysis of the quotes I have selected, in my own opinion as a translator and as an assistant professor of translation I see Google Translate will make some breakthroughs and may be one day we will see a big progress if translators and computer programmers work together, particularly in regard to the linguistic dimension of morphology. It is correct that regarding some quotes the results were frustrating but there were developments in some quotes. Meanwhile the distance between the two forms of the agency still requires more to fill the gap as per the intersections of social and cultural dimensions. It also worth mentioning that up to now, according to the translation provided by Google Translate, it is very early for it to bridge the gap. Some unacceptable errors still occur. 
Lucas Nunes Vieira \& Elisa Alonso (2020) investigated management and production perspectives on the use of MT in professional translation. Their analysis showed how MT can add uncertainty to translation services and in turn exacerbate issues relating to miscommunication and work fragmentation. They also discussed how the increasingly common use of MT in the language industry can change translation projects. Their analysis also showed how the makeup of service provision networks risks restricting translators' field of influence to the text while alienating them from wider aspects of a project's business strategy. They argued that this imbalance in the translators' role affects how MT use is perceived and negotiated, which has consequences for those in the group of management as well as the group of production. Based on their analysis of the interviews, they made two suggestions. First, they invited for increased translator involvement in estimation and clientcommunication aspects of translation projects as a way of helping to foster environments in which translators play broader and more integrated roles in translation supply chains. Second, they argued that discussing MT as a 'threat' can detract attention from more serious problems concerning unrealistic perceptions of the technology, mismatched expectations and the often-restricted position translators occupy in service provision networks.

Brynjolfsson and McAfee (2014) argued that machine learning is deemed to be part of a new technological wave often called the second machine age (SMA). Views on the SMA's potential for disrupting human labor vary widely, ranging from those who believe it presents positive opportunities for human-computer interaction (ibid) to those who argue that predictions of economic growth and innovation associated with the SMA are overstated (e.g. Gordon 2014). Irrespective of one's position on the SMA and its disruptive potential, certain trends in employment and the economy observed over the past few decades are quite striking. These trends include a polarization of jobs (Autor 2015; Goos and Manning 2007; OECD 2017) and a reversal in the demand for cognitive labor (Beaudry, Green, and Sand 2013). Surprisingly, these phenomena are often ignored in current debates on trends in professional translation.

A recent report by the Translation Automation User Society (TAUS) places great emphasis on creative tasks as the key to translators' sustainability. In describing translators' place in the future of the translation industry, the report states that translators will turn into writers, consultants on cultural issues, and critical to brand and product success (Massardo and van der Meer 2017, 27). While these predictions are sensible, it is worth noting that in the context of functional and target-oriented approaches to translation - see, for more details, the following part about translation or transcreationthe role of the translator may already accommodate most if not all these aspects. If translators do not currently operate in these capacities, the issue is likely to lie with current working models, rather than with the profession itself.

\subsection{Translation or Transcreation}

In the field of translation studies, contrasting terms have been used to refer to sharply different translation approaches, which are all adopted in attempts to achieve equivalence across the "free" to "literal" translation spectrum. There are, for example, "dynamic equivalence" (Nida, 1964) versus "formal equivalence" (Catford, 1965), "domestication" versus "foreignization" (Paloposki, 2011), "translator's invisibility" versus "translator's visibility (Venuti, 2008), "covert translation" versus "overt translation" (House, 2001) and "thick" versus "thin" translation (Hermans,2003). The farther a translated text has departed from the original, the more it is tilted towards the 'free' end of the spectrum, and the greater it becomes transcreative. Cited by (Jing Fang and Zhongwei Song,2014).

Transcreation aim is to make sure that "the target text is the same as the source text in every aspect; the message it conveys, the style, the images and emotions it evokes and its cultural background" (Balemans, 2013). 'Creation' only comes into play when, with all the possible considerations taken, the transferred meaning of a concept, an idea, a product or service is still believed unable to strike the chord with the intended audience from one language to another language. According to Stibbe, the aim of transcreation is in essence to yield something that translation in itself won't be able to achieve (Stibbe, 2009).

In his paper, which investigated the concept of transcreation mainlyin an advertising and marketing context, Daniel Pedersen,2014 noted that "translation proper is perceived as transferring words from one language to another, while transcreation implies something more". Through the analysis he made, Daniel also put that transcreation transfers brands and messages from on culture to another. The 
dimension of culture is crucial when we deal with the subject matter of this paper, particularly in regard to translating of Arabic literary texts, because Google Translate could easily transfer words from one language to another, correctly or wrongly, but this is not enough when dealing with the literary Arabic texts of love in the classic poetry or even the modern poetry. This will appear evidently in the details of the analysis of the sample selected as well as in the comparison between the two translations (the translation provided by the author described as human-based translation and the translation produced by Google Translate described as machine-based translation).

Also by knocking on the point of the culture this will prove that the texts this study deals with are in need to transcreation, not translation only, particularly when talking about poetry because the translator in this case must live and feel and enjoy the emotional status of the poet. So, the computerassisted translation alone is not enough, but still it requires the support by translators as human agents. Now we see computer is required even in the application of medicine and surgery, but if a patient in need to undergo a computer-assisted surgery, he/she would need a highly competent and creative surgeon behind that computer. We see computer is required even in the application of engineering and architecture, but if you a man wants to build a tower, the computer alone could not do that without support from creative engineers. The same thing to translation, machines of translation alone are not enough to manipulate the literary texts for many implications linked to language, and then accordingly transcreation is requested here.

\subsection{Sample of the Study}

In this part the researcher concluded a comparison between his translation and the one of Google Translate. The study sample includes (6) quotes from Arabic poetry among classic poems. As an evidence the author provided the links of the translated quotes from Arabic into English according to each quote number in the part of the appendices. The author also deliberately meant to enter $\left(^{*}\right)$ as an indication that the work was done by him. For further documentation to the evidences the author took screenshots for the translated quotes. This part also provides a brief about the poets of the selected quotes.

\section{* The first quote}

\section{The Arabic quote}

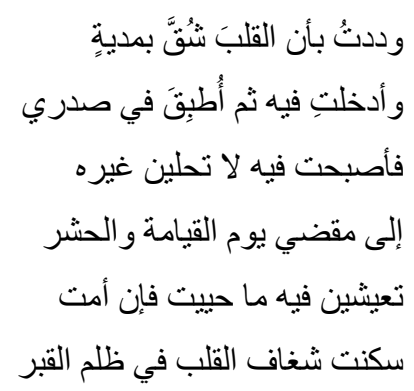

\section{The quote as google translate:}

I wanted the heart to be slit with a span

I inserted it and then it was applied to my chest

I became in it do not solve others

To spend the Day of Resurrection and Hashr

You live in it as long as you live, but the nation

The endurance of the heart inhabited the injustice of the grave

\section{My translation:}

I wish if my heart was slit by a blade

And you (my love) were put inside it, and my chest closed again

And you (my darling) became in it unable to move to another place,

Till Resurrection Day 
To live inside it a long my life, and when I became dead

You live in its endocardium in the grave shade

\section{Comment and Analysis}

In this quote Google translated every word, or word by word. Google was also unable to process the pronouns included in the Arabic text. It does not only translate the words, but it translates the letters of these words and was misled by the letters of the Arabic word (ظلم) in the last line. Here it means (darks) not (injustice), but for the two words have the same spelling, the machine went wrong. The same wrong occurred with the words (span), (solve), and (nation) respectively. In other words, the machine does not consider the diacritics of the Arabic words. This a problem relevant to the words' morphemes.

Google failed to convey the love image depicted by the poet, but it distorted that totally and was unable to translate the emotional case which invaded the heart of Ibn Hazm (the poet).

I underlined the mistakes in a trial to count the mistakes made by the machine translation, but nothing is correct.

\section{AboutThe poet:}

Ibn Hazm, in full AbūMuhammad Alī ibn Ahmad ibn Sa ìd Ibn Hazm, (born November 7, 994, Córdoba, Caliphate of Córdoba-died August 15, 1064, Manta Līsham, near Sevilla), Muslim litterateur, historian, jurist, and theologian of Islamic Spain, famed for his literary productivity, breadth of learning, and mastery of the Arabic language. One of the leading exponents of the Zāhirī (Literalist) school of jurisprudence, he produced some 400 works, covering jurisprudence, logic, history, ethics, comparative religion, and theology, and The Ring of the Dove, on the art of love. For more about the poet read (https://en.wikipedia.org/wiki/Ibn_Hazm).

\section{The second quote:}

\section{The Arabic quote:}

$$
\begin{aligned}
& \text { وَدِّع هُرَيرَةَ إِنَّ الرَكَبَ مُرنَحِلُ }
\end{aligned}
$$

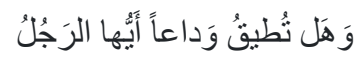

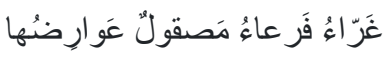

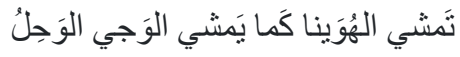

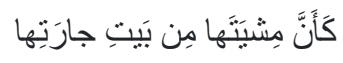

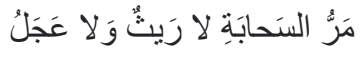

The quote as google translate:

Farewell to Huraira, the passenger is traveling

Do you tolerate goodbye, man

The glow of the glacier branches are its symptoms

$\underline{\text { Huahina walks like muddy faces }}$

As if walking her from the house of her neighbor

Pass by the cloud, neither heir nor calf

My translation:

Go to say goodbye for Huraira

Her tribe caravan is moving

But could you tolerate that farewell, you man?

A white lady with a long hair and light teeth 
She walks slowly as if she is barefoot in a mud

She passes from her neighbor house

As the cloud, neither slow nor hasty

\section{Comment and analysis:}

In the first line the machine astonished me because it provided the person name (the poet's darling) though there is a lexical meaning in English for Huraira, which is (kitten).

Again, in the remaining lines the machine started to repeat the same problem translating the words according to their letters as in the example of the previous first quote. That appears in translation of the word as (calf), (glow), (glacier), and (branch). These words provided by Google Translate as a type of machine translation are never relevant to the meaning targeted by the poet. Sure, such translation will mislead the reader. If the reader is Arabic speaker has a knowledge with English, he/she will burst in laugh. For those who are not Arabian but speak English will also directly note that it is machine translation because the mess in words orders is clear which is another problem of (MT). The meaningless transliteration is also available here as in the word (Huahina)

This stanza is from the poem of Al-Asha, a famous poet in the Arab world before Islam. He is one of the most well-known seven poets at that era. Their poems were written with gold water and showed on the wall of Al-Kaaba in Mecca, one of the two holy places for Muslims in KSA. For more about the poet search the link: (https://en.wikipedia.org/wiki/Al-A\%27sha).

\section{* The third quote:}

\section{The Arabic quote:}

\section{The quote as google translate:}

Wherever you are, what is between me and what you love is the distance between me and the calamities.

\section{My translation:}

I wish this far distance between me and my loved people is the distance between me and the calamities.

\section{Comment and analysis:}

The poet here expresses he is suffering from the far distance between him and the ones whom he loves while at the same time he is so near to those whom he hates that he called them calamities.

When we compare the two translations, we see that google is still far to convey the emotions of the Arab poets though it is one verse, not a stanza.

\section{About the poet:}

This verse is for Abū al-TayyibAhmad ibn Al-Husayn Al-Mutanabbī Al-Kind̄̄ (915 -965) from alKüfah, Iraq, was a famous 'Abbāsid Arab poet at the court of Sayf al-Dawla in Aleppo, and for whom he composed 300 folios of poetry. As one of the greatest, most prominent and influential poets in the Arabic language, much of his work has been translated into over 20 languages worldwide. His poetry largely revolves around praising the kings he visited during his lifetime. He started writing poetry when he was nine years old. He is well known for his sharp intelligence and wittiness. AlMutanabbi had great pride in himself through his poetry. Among the topics he discussed were courage, the philosophy of life, and the description of battles. Many of his poems were and still are widely spread in today's Arab world and are thought to be proverbial. His great talent brought him very close to many leaders of his time. He praised those leaders and kings for money and gifts. His poetic style earned him great popularity in his time. For more details see (https://en.wikipedia. org/wiki/Al-Mutanabbi).

\section{* The fourth quote:}

\section{The Arabic quote:}

$$
\text { ولا أحمل الحقد القديم عليهم وليس سيد القوم من يحمل الحقد }
$$

\section{The quote as google translate}


I do not carry the old hatredon them and it is not the master of the people who carries the hatred

\section{My translation:}

I do not bear in my heart any old grudge against them as the master of his tribe does not bear grudge

\section{Comment and analysis:}

The difference between the two translation appears in using the correct preposition (on) where it does not convey the true meaning as (against) does. In addition to the difference in the selectivity of the words for the word (grudge) conveys the meaning of this verse better than (hatred). Anyhow we can say that Google Translate made a good approach. It was about to shoot the target meticulously. Some Arab linguist may think Google was not about to shoot the target if they look at it in an extreme vision as there is no absolute synonymy in Arabic language. (hatred) may be clear explicit while (grudge) is hidden and implicit and rarely becomes clear.

\section{AboutThe poet:}

The poet of this verse was Abu YūsufYa'qūb ibn 'Isḥāqaṣ-Ṣabbāḥ al-Kindī (/æl'kındi/; Latin: Alkindus; c.801-873AD) was an Arab Muslim philosopher, polymath, mathematician, physician and musician. Al-Kindi was the first of the Islamic peripatetic philosophers, and was hailed as the "father of Arab philosophy". See https://en.wikipedia.org/wiki/Al-Kindi

\section{The fifth quote:}

\section{The Arabic quote:}



The quote as google translate

You are my homework

You are my job and my work

O kisses in my prayers

If I stand praying

\section{My translation:}

You are my imposed prayers as my additional prayers

You are my talks and my works

The direction where I direct my face

When I stand for pray

\section{Comment and analysis:}

Again, google translates the word according to the letters only neglecting the pattern of Arabic words

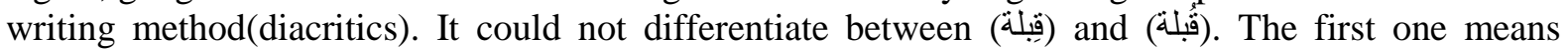
(direction), which is meant by the poet while the second one means in English (kiss) and it is not the intended meaning here.

In the first line we see a googled translation that never conveys the culture and the background of the poet. The dimension of the culture is essential when we translate others literary works. It worth mentioning that the first line of this verse included two religious terms indicate to the poet religious culture in an awesome euphemism narrates that his loved people are everything in his life. Another dimension that some time could not be received even by human-based translation that some critics claims the that the poem is a symbolic and the poet target God love, not a true loved lady.

\section{About the poet:}

Ibn al-Farid or Ibn Farid; ( Umar ibn 'Alī ibn al-Fārid) (22 March 1181 - 1234) was an Arab poet. He was born in Cairo to parents from Hama in Syria, lived for some time in Mecca, and died in Cairo. His poetry is entirely Sufi, and he was esteemed as the greatest mystic poet of the 
Arabs. Some of his poems are said to have been written in ecstasies. For more details about the poet see: (https://en.wikipedia.org/wiki/Ibn_al-Farid)

\section{* The sixth quote:}

\section{The Arabic quote:}

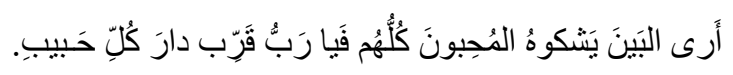

\section{The quote as google translate}

I see between all the lovers that the lovers doubt in the Lord, near the home of all Habib.

\section{My translation:}

I see that all lovers complain from the far distance of their darlings' houses

Please my god make close the house of every darling

\section{Comment and analysis:}

Again and again, may be for more than three times in these six short quotes Google Translate approves it suffers from the same problem of translating the words according to their letters only without giving attention to the diacritics of the Arabic words.

In this verse, this problem appears in the words; (البين) and (يثكو). It translated (البين) as (between), and(يشكو) as (doubt)whereas the correct translation for these two words are (far distance) and (complain) respectively.

Another mistake in the translation regarding this verse is that Google Translate transliterated the Arabic word (حبي) as (Habib) as if it is a proper noun (person name), but it is not. It is the equivalent Arabic for the English word (darling) as seen in my translation.

The machine-based translation here is totally far away. It was not able to manipulate the verse.

\section{About the poet:}

Abu al-Fadl Abbas Ibn al-Ahnaf, (750 -809), was an Arab Abbasid poet from the clan of Hanifa. His work consists solely of love poems (ghazal). It is "primarily concerned with the hopelessness of love, and the personae in his compositions seems resigned to a relationship of deprivation".The vocabulary he chose was simple and his style is fluent and easy. For more details about the poet see( https://en.wikipedia.org/wiki/Abbas_Ibn_al-Ahnaf).

\section{CONClusion}

In the following points a summary for the linguistic aspects that google was unable to manipulate from Arabic into English and may be able to process them in the future if it was developed accordingly. These aspects include:

- The diacritics of the Arabic words: as in the different quotes the Arabic words shape an ambiguity to the machine because of the diacritics. Though the researcher made his best to put the requested diacritic, but still Google Translate unable to fix the targeted word. In addition to the diacritics it is better for the programmers of this electronic program to give their care to the nunation marks of Arabic too. This will improve the translation of google to a big extent. According to translation analysis of the above quotes, the diacritics problem is the most and common problem that encounter google to translate from in Arabic into English. The letters are same, and the diacritics are different, but the machine does not differentiate, this why I could say up to now "the machine is blind". Solving this problem will make a big breakthrough in the field of google translation.

- The pronouns in Arabic language: in Arabic language, in contrary to English language, the pronouns are divided into two types according to their morphemes; some pronouns are clear, but some are hidden. As in the translation of the sample quotes the machine was so far from processing of the hidden Arabic pronouns. This shapes another ambiguity to the machine in processing the translation. The translation provided by Google Translate showed that it is good to some extent in translation of words relevant to clear pronouns. 
- Polysemous Arabic words: the $6^{\text {th }}$ quote discloses that google was unable to translate the polysemous words as in the Arabic word (البين), which has two meanings without the definite article (see the Comment and analysis on the translation).

- Transliteration: also, the $6^{\text {th }}$ quote showed that Google Translate transliterated a meaningful word that should not be transliterated except in case it is a proper noun (see the Comment and analysis on the translation). This point with the two points before it confirms the importance of human agency according to some scholars as discussed in the previous parts of this study.

- Textual cohesion: Google Translate showed a detrimental effect on textual cohesion as seen in the translation of the quotes of the study sample.

- Euphemism: this is clear in the religious term used by the poet of the $5^{\text {th }}$ quote of the sample. Google was unable to manipulate. Again, the necessity for human agency appears clearly (see the Comment and analysis about the translation of the $5^{\text {th }}$ quote). This also resulted in failing of the ability of conveyance the cultural background of the poet, which is another aspect added to the linguistic aspect. It is known that poetry study is not for language only, but it includes other dimensions assist in the study of sociology and culture.

- Prepositions: the $4^{\text {th }}$ quote disclosed that the machine was not able to select the exactly needed preposition that lead to a semantic change.

- Arabic word of wishing: in Arabic language there are wishing words as (ليت). Google was unable to manipulate such words though it is easy, for more illustration (see the $3^{\text {rd }}$ quote translation).

\section{APPENDICES:}

Appendix (1): Links of the quotes:

Link of the first quote:

https://translate.google.com/\#view=home\&op=translate\&sl=ar\&tl=en\&text=\%D9\%88\%D8\%AF\%D8 \%AF\%D8\%AA\%D9\%8F\%20\%D8\%A8\%D8\%A3\%D9\%86\%20\%D8\%A7\%D9\%84\%D9\%82\%D9\% 84\%D8\%A8\%D9\%8E\%20\%D8\%B4\%D9\%8F\%D9\%82\%D9\%91\%D9\%8E\%20\%D8\%A8\%D9\%85 \%D8\%AF\%D9\%8A\%D8\%A9\%D9\%8D\%0A\%D9\%88\%D8\%A3\%D8\%AF\%D8\%AE\%D9\%84\%D8 \%AA\%D9\%90\%20\%D9\%81\%D9\%8A\%D9\%87\%20\%D8\%AB\%D9\%85\%20\%D8\%A3\%D9\%8F\% D8\%B7\%D8\%A8\%D9\%90\%D9\%82\%D9\%8E\%20\%D9\%81\%D9\%8A\%20\%D8\%B5\%D8\%AF\%D 8\%B1\%D9\%8A\%0A\%D9\%81\%D8\%A3\%D8\%B5\%D8\%A8\%D8\%AD\%D8\%AA\%20\%D9\%81\%D 9\%8A\%D9\%87\%20\%D9\%84\%D8\%A7\%20\%D8\%AA\%D8\%AD\%D9\%84\%D9\%8A\%D9\%86\%20 \%D8\%BA\%D9\%8A\%D8\%B1\%D9\%87\%20\%0A\%D8\%A5\%D9\%84\%D9\%89\%20\%D9\%85\%D9\% 82\%D8\%B6\%D9\%8A\%20\%D9\%8A\%D9\%88\%D9\%85\%20\%D8\%A7\%D9\%84\%D9\%82\%D9\%8A \%D8\%A7\%D9\%85\%D8\%A9\%20\%D9\%88\% D8\%A7\%D9\%84\%D8\%AD\%D8\%B4\%D8\%B1\%20\% 0A\%D8\%AA\%D8\%B9\%D9\%8A\%D8\%B4\%D9\%8A\%D9\%86\%20\%D9\%81\%D9\%8A\%D9\%87\%2 0\%D9\%85\%D8\%A7\%20\%D8\%AD\%D9\%8A\%D9\%8A\%D8\%AA\%20\%D9\%81\%D8\%A5\%D9\%86 \%20\%D8\%A3\%D9\%85\%D8\%AA\%20\%0A\%D8\%B3\%D9\%83\%D9\%86\%D8\%AA\%20\%D8\%B4\% D8\%BA\%D8\%A7\%D9\%81\%20\%D8\%A7\%D9\%84\%D9\%82\%D9\%84\%D8\%A8\%20\%D9\%81\%D9 \%8A\%20\%D8\%B8\%D9\%84\%D9\%85\%20\%D8\%A7\%D9\%84\%D9\%82\%D8\%A8\%D8\%B1\%0A\%0 $\mathrm{A}^{*}$

Link of the second quote:

https://translate.google.com/\#view=home\&op=translate\&sl=ar\&tl=en\&text=\%D9\%88\%D9\%8E\%D8 \%AF\%D9\%91\%D9\%90\%D8\%B9\%20\%D9\%87\%D9\%8F\%D8\%B1\%D9\%8E\%D9\%8A\%D8\%B1\% D9\%8E\%D8\%A9\%D9\%8E\%20\%D8\%A5\%D9\%90\%D9\%86\%D9\%91\%D9\%8E\%20\%D8\%A7\%D9 \%84\%D8\%B1\%D9\%8E\%D9\%83\%D8\%A8\%D9\%8E\%20\%D9\%85\%D9\%8F\%D8\%B1\%D8\%AA\% D9\%8E\%D8\%AD\%D9\%90\%D9\%84\%D9\%8F\%0A\%D9\%88\%D9\%8E\%D9\%87\%D9\%8E\%D9\%84 \%20\%D8\%AA\%D9\%8F\%D8\%B7\%D9\%8A\%D9\%82\%D9\%8F\%20\%D9\%88\%D9\%8E\%D8\%AF\% D8\%A7\%D8\%B9\%D8\%A7\%D9\%8B\%20\%D8\%A3\%D9\%8E\%D9\%8A\%D9\%91\%D9\%8F\%D9\%8 7\%D8\%A7\%20\%D8\%A7\%D9\%84\%D8\%B1\%D9\%8E\%D8\%AC\%D9\%8F\%D9\%84\%D9\%8F\%0A \%D8\%BA\%D9\%8E\%D8\%B1\%D9\%91\%D8\%A7\%D8\%A1\%D9\%8F\%20\%D9\%81\%D9\%8E\%D8\% B1\%D8\%B9\%D8\%A7\%D8\%A1\%D9\%8F\%20\%D9\%85\%D9\%8E\%D8\%B5\%D9\%82\%D9\%88\%D9 \%84\%D9\%8C\%20\%D8\%B9\%D9\%8E\%D9\%88\%D8\%A7\%D8\%B1\%D9\%90\%D8\%B6\%D9\%8F\% 
D9\%87\%D8\%A7\%0A\%D8\%AA\%D9\%8E\%D9\%85\%D8\%B4\%D9\%8A\%20\%D8\%A7\%D9\%84\%D 9\%87\%D9\%8F\%D9\%88\%D9\%8E\%D9\%8A\%D9\%86\%D8\%A7\%20\%D9\%83\%D9\%8E\%D9\%85\% D8\%A7\%20\%D9\%8A\%D9\%8E\%D9\%85\%D8\%B4\%D9\%8A\%20\%D8\%A7\%D9\%84\%D9\%88\%D 9\%8E\%D8\%AC\%D9\%8A\%20\%D8\%A7\%D9\%84\%D9\%88\%D9\%8E\%D8\%AD\%D9\%90\%D9\%84 \%D9\%8F\%0A\%D9\%83\%D9\%8E\%D8\%A3\%D9\%8E\%D9\%86\%D9\%91\%D9\%8E\%20\%D9\%85\% D9\%90\%D8\%B4\%D9\%8A\%D9\%8E\%D8\%AA\%D9\%8E\%D9\%87\%D8\%A7\%20\%D9\%85\%D9\%9 0\%D9\%86\%20\%D8\%A8\%D9\%8E\%D9\%8A\%D8\%AA\%D9\%90\%20\%D8\%AC\%D8\%A7\%D8\%B1 \%D9\%8E\%D8\%AA\%D9\%90\%D9\%87\%D8\%A7\%0A\%D9\%85\%D9\%8E\%D8\%B1\%D9\%91\%D9\% 8F\%20\%D8\%A7\%D9\%84\%D8\%B3\%D9\%8E\%D8\%AD\%D8\%A7\%D8\%A8\%D9\%8E\%D8\%A9\% D9\%90\%20\%D9\%84\%D8\%A7\%20\%D8\%B1\%D9\%8E\%D9\%8A\%D8\%AB\%D9\%8C\%20\%D9\%88 \%D9\%8E\%D9\%84\%D8\%A7\%20\%D8\%B9\%D9\%8E\%D8\%AC\%D9\%8E\%D9\%84\%D9\%8F\%0A\% $0 \mathrm{~A}^{*}$

link of the third quote

https://translate.google.com/\#view=home\&op=translate\&sl=ar\&tl=en\&text=\%D9\%81\%D9\%8E\%D9 \%8A\%D8\%A7\%20\%D9\%84\%D9\%8E\%D9\%8A\%D8\%AA\%D9\%8E\%20\%D9\%85\%D8\%A7\%20\% D8\%A8\%D9\%8E\%D9\%8A\%D9\%86\%D9\%8A\%20\%D9\%88\%D9\%8E\%D8\%A8\%D9\%8E\%D9\%8 A\%D9\%86\%D9\%8E\%20\%D8\%A3\%D9\%8E\%D8\%AD\%D9\%90\%D8\%A8\%D9\%91\%D9\%8E\%D8 \%AA\%D9\%8A\%20\%20\%20\%20\%20\%20\%D9\%85\%D9\%90\%D9\%86\%D9\%8E\%20\%D8\%A7\%D 9\%84\%D8\%A8\%D9\%8F\%D8\%B9\%D8\%AF\%D9\%90\%20\%D9\%85\%D8\%A7\%20\%D8\%A8\%D9 \%8E\%D9\%8A\%D9\%86\%D9\%8A\%20\%D9\%88\%D9\%8E\%D8\%A8\%D9\%8E\%D9\%8A\%D9\%86\% D9\%8E\%20\%D8\%A7\%D9\%84\%D9\%85\%D9\%8E\%D8\%B5\%D8\%A7\%D8\%A6\%D9\%90\%D8\%A $8 \% \mathrm{D} 9 \% 90 \% 0 \mathrm{~A} \% 0 \mathrm{~A}^{*}$

link of the fourth quote:

https://translate.google.com/\#view=home\&op=translate \&sl=ar\&tl=en\&text=\%D9\%88\%D9\%84\%D8 \%A7\%20\%D8\%A3\%D8\%AD\%D9\%85\%D9\%84\%20\%D8\%A7\%D9\%84\%D8\%AD\%D9\%82\%D8 \%AF\%20\%D8\%A7\%D9\%84\%D9\%82\%D8\%AF\%D9\%8A\%D9\%85\%20\%D8\%B9\%D9\%84\%D9\% 8A\%D9\%87\%D9\%85\%20\%D9\%88\%D9\%84\%D9\%8A\%D8\%B3\%20\%D8\%B3\%D9\%8A\%D8\%AF \%20\%D8\%A7\%D9\%84\%D9\%82\%D9\%88\%D9\%85\%20\%D9\%85\%D9\%86\%20\%D9\%8A\%D8\%A D\%D9\%85\%D9\%84\%20\%D8\%A7\%D9\%84\%D8\%AD\%D9\%82\%D8\%AF\%D8\%A7\%0A\%0A*

link of the fifth quote:

https://translate.google.com/\#view=home\&op=translate\&sl=ar\&tl=en\&text=\%D8\%A3\%D9\%86\%D9 \%92\%D8\%AA\%D9\%8F\%D9\%85\%20\%D9\%81\%D9\%8F\%D8\%B1\%D9\%8F\%D9\%88\%D8\%B6\% D9\%8A\%20\%D9\%88\%D9\%86\%D9\%8E\%D9\%81\%D9\%84\%D9\%8A\%0A\%D8\%A3\%D9\%86\%D9 \%92\%D8\%AA\%D9\%8F\%D9\%85\%20\%D8\%AD\%D9\%8E\%D8\%AF\%D9\%8A\%D8\%AB\%D9\%8A \%20\%D9\%88\%D8\%B4\%D9\%8F\%D8\%BA\%D9\%92\%D9\%84\%D9\%8A\%0A\%D9\%8A\%D8\%A7\% 20\%D9\%82\%D9\%90\%D8\%A8\%D9\%92\%D9\%84\%D9\%8E\%D8\%AA\%D9\%90\%D9\%8A\%20\%D9 \%81\%D9\%8A\%20\%D8\%B5\%D9\%84\%D8\%A7\%D8\%AA\%D9\%8A\%0A\%D8\%A5\%D8\%B0\%D8 \%A7\%20\%D9\%88\%D9\%8E\%D9\%82\%D9\%8E\%D9\%81\%D9\%92\%D8\%AA\%D9\%8F\%20\%D8\% A3\%D9\%8F\%D8\%B5\%D9\%84\%D9\%91\%D9\%8A\%0A\%0A*

link of the sixth quote:

https://translate.google.com/\#view=home\&op=translate\&sl=ar\&tl=en\&text=\%D8\%A3\%D9\%8E\%D8 \%B1\%D9\%89\%20\%D8\%A7\%D9\%84\%D8\%A8\%D9\%8E\%D9\%8A\%D9\%86\%D9\%8E\%20\%D9\% 8A\%D9\%8E\%D8\%B4\%D9\%83\%D9\%88\%D9\%87\%D9\%8F\%20\%D8\%A7\%D9\%84\%D9\%85\%D9 \%8F\%D8\%AD\%D9\%90\%D8\%A8\%D9\%88\%D9\%86\%D9\%8E\%20\%D9\%83\%D9\%8F\%D9\%84\% D9\%8F\%D9\%91\%D9\%87\%D9\%8F\%D9\%85\%20\%D9\%81\%D9\%8E\%D9\%8A\%D8\%A7\%20\%D8 \%B1\%D9\%8E\%D8\%A8\%D9\%8F\%D9\%91\%20\%D9\%82\%D9\%8E\%D8\%B1\%D9\%90\%D9\%91\% D8\%A8\%20\%D8\%AF\%D8\%A7\%D8\%B1\%D9\%8E\%20\%D9\%83\%D9\%8F\%D9\%84\%D9\%90\%D9 \%91\%20\%D8\%AD\%D9\%8E\%D9\%80\%D8\%A8\%D9\%8A\%D8\%A8\%D9\%90.\%0A\%0A* 
Appendix (2): Screenshots of the quote

Quote1:

$\equiv$ Google Translate

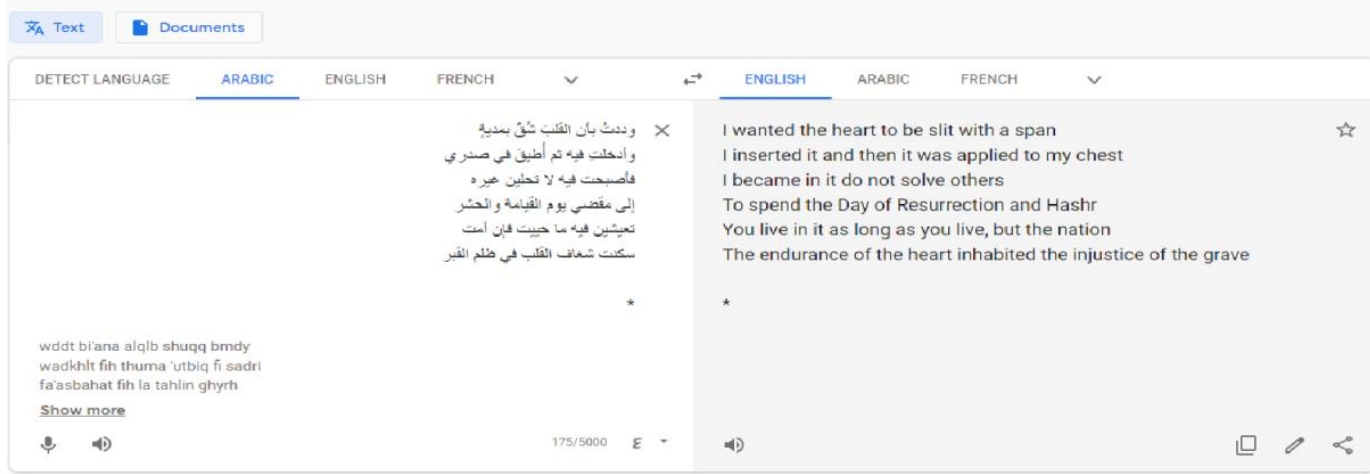

Quote2:

$\equiv$ Google Translate

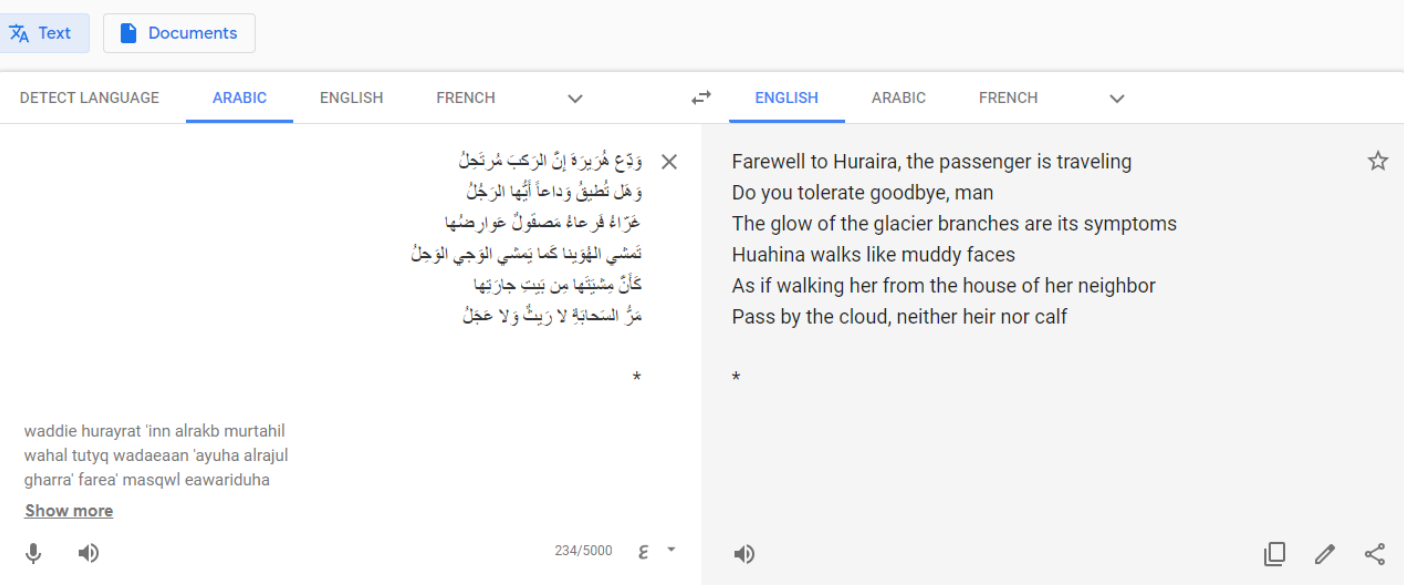

Quote3:

Google Translate

Text

Documents

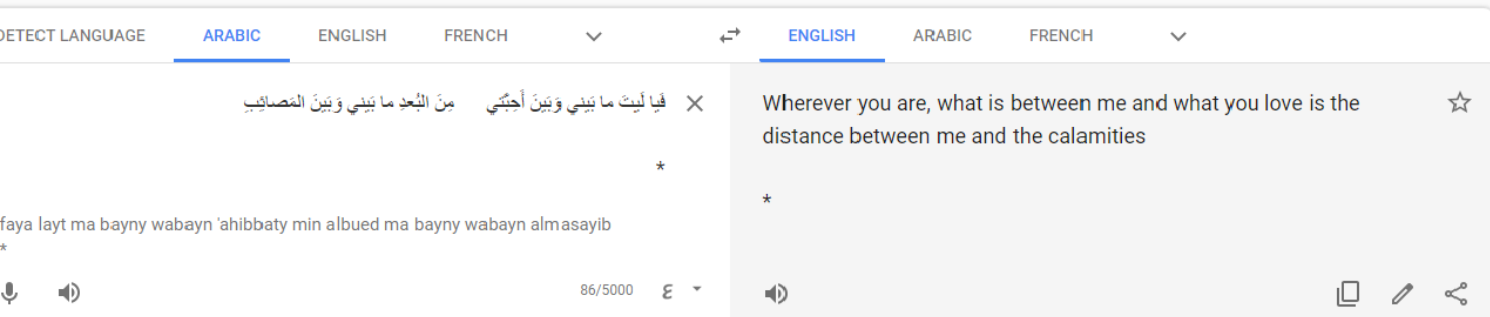

Quote4:

$\equiv$ Google Translate

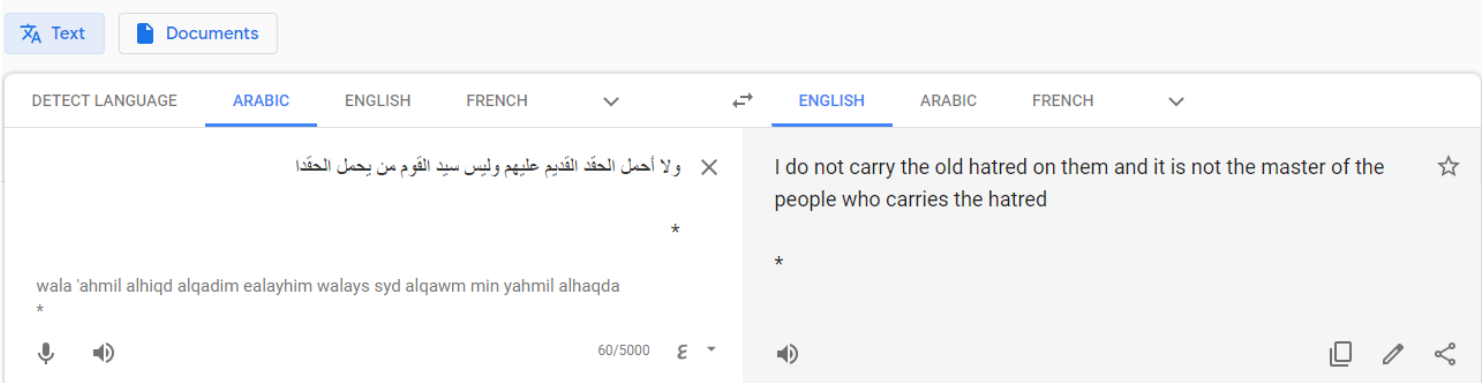


Quote5:

$\equiv$ Google Translate

Quote6:

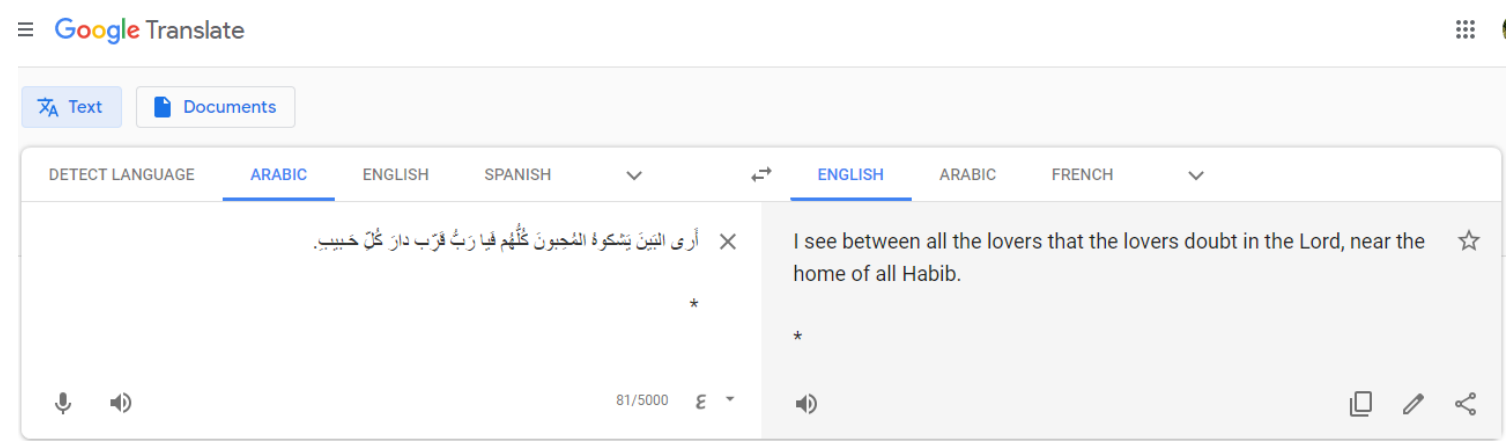

\section{REFERENCES}

[1] Alcina, Amparo. 2008. Translation technologies: Scope, tools and resources. Target, 20(1): 79-102.

[2] Alonso, Elisa, and Lucas N. Vieira. 2017. "The Translator's Amanuensis 2020." The Journal of Specialised Translation 28: 345-361.

[3] Alves, Fabio, and TâniaLiparini Campos. 2009. Translation technology in time: Investigating the impact of translation memory systems and time pressure on types of internal and external support. In Behind the mind: Methods, models and results in translation process research, ed. Susanne Göpferich, ArntLykkeJakobsen, and Inger M. Mees, 191-218. Copenhagen: Samfundslitteratur Press.

[4] Austermühl, Frank. 2001. Electronic tools for translators, Manchester: St Jerome.

[5] Autor, David H. 2015. "Why Are There Still so Many Jobs? The History and Future of Workplace Automation." Journal of Economic Perspectives 29 (3): 3-30. doi: 10.1257/jep.29.3.3.

[6] Baker, Mona. 2006. Translation and conflict. A narrative account, London: Routledge.

[7] Balemans, P. 2013. The ATA Compass: Your guide to translation in the global market. Retrieved in June 2014 from http:/theatacompass.org/2013/08/28/transcreation-translating-andrecreating/.

[8] Baumgarten, Stefan, and Jordi Cornellà-Detrell, eds. 2017. "Translation in Times of Techno capitalism." Target 29 (2): 193-200. doi: 10.1075/target.29.2.001.

[9] Beaudry, Paul, David A. Green, and Benjamin M. Sand. 2013. "The Great Reversal in the Demand for Skill and Cognitive Tasks." National Bureau of Economic Research Working Paper Series No. 18901. doi:10.3386/w18901.

[10] Boéri, Julie. 2008. A narrative account of the Babels vs. Naumann controversy. The Translator, 14(1): 2150.

[11] Bowker Lynne. 2007. Translation memory and "text". In Lexicography, terminology, and translation. Text-based studies in honour of Ingrid Meyer, Lynne Bowker. Ottawa University of Ottawa Press. 175 187

[12] Bowker, Lynne. 2005. Productivity vs quality? A pilot study on the impact of translation memory systems. Localisation Focus, 4(1): 13-20.

[13] Brynjolfsson, Erik, and Andrew McAfee. 2014. The Second Machine Age: Work, Progress, and Prosperity in a Time of Brilliant Technologies. New York and London: W. W. Norton \& Company.

[14] Cadwell, Patrick, Sharon O'Brien, and Carlos S. C. Teixeira. 2018. "Resistance and Accommodation: Factors for the (Non-) Adoption of Machine Translation among Professional Translators." Perspectives 26 (3): 301-321. doi: 10.1080/0907676X.2017.1337210. 
[15] Catford, J. C. 1965. A linguistic theory of translation: an essay in applied linguistics. London: Oxford University Press.

[16] Cronin, Michael. 2013. Translation in the Digital Age. London and New York: Routledge.

[17] Daniel, Pederson. 2024 "Exploring the concept of transcreation - transcreation as 'more than translation'?". Cultus,https://iris.unipa.it/retrieve/handle/10447/130535/197987/cultus\#page=57.

[18] Dillon, Sarah and Fraser, Janet. 2006. Translators and TM: An investigation of translators' perceptions of translation memory adoption. Machine Translation, 20(2): 67-79.

[19] Fulford Heather, and Joaquin Granell-Zafra. 2005. Translation and technology: A study of UK freelance translators. JoSTrans - The Journal of Specialised Translation 4, http://www.jostrans.org/issue04/art_ fulford_zafra.php.

[20] Fulford, Heather. 2001. Translation tools: An exploratory study of their adoption by UK freelance translators. Machine Translation, 16(4): 219-32.

[21] Giddens, Anthony. 1986. The constitution of society. Outline of the theory of structuration, Berkeley, CA: University of California Press.

[22] Goos, Maarten, and Alan Manning. 2007. "Lousy and Lovely Jobs: The Rising Polarization of Work in Britain." The Review of Economics and Statistics 89 (1): 118-133. doi: 10.1162/rest.89.1.118.

[23] Gordon, Robert J. 2014. "The Demise of U.S. Economic Growth: Restatement, Rebuttal, and Reflections." National Bureau of Economic Research Working Paper Series No. 19895. doi:10.3386/w19895.

[24] Hermans, T. 2003. 'Cross-cultural translation studies as thick translation', Bulletin of SOAS, 66 (3), $380-$ 89.

[25] House, J. 2001. "How do we know when a translation is good?" In E. Steiner \& C. Yallop (Eds.), Exploring translation and multilingual text production: beyond content. Berlin/New York: Mouton de Gruyter, 127- 160.

[26] Inghilleri, Moira. 2007. National sovereignty versus universal rights: Interpreting justice in a global context. Social Semiotics, 17(2): 195-212.

[27] J. Fang, Z.Song. 2014 "Exploring the Chinese Translation of Australian Health Product Labels: Are they selling the same thing?".Cultus, https://iris.unipa.it/retrieve/handle/10447/130535/197987/cultus\#page=72.

[28] Jones, Matthew. 1999. Information systems and the double mangle: Steering a course between the Scylla of embedded structure and the Charybdis of strong symmetry. In Information systems. Current issues and future changes, ed. Tor Jermud Larsen, Linda Levine, and Janice I. deGross, 287-302. Laxenburg: International Federation for Information Processing.

[29] Kenny, Dorothy. 1999. CAT tools in an academic environment: What are they good for?.Target, 11(1): 65-82.

[30] Kinnunen, Tuija , and Kaisa Koskinen 2010 . Translators' agency. Tampere University Press.

[31] Lagoudaki, Elina. 2006. Translation memory systems. Enlightening users' perspective, London: Imperial College London.

[32] Latour, Bruno. 2005. Reassembling the social. An introduction to actor-network-theory, Oxford: Oxford University Press.

[33] Läubli, Samuel and Orrego-Carmona, David. 2017. "When Google Translate is Better Than Some Human Colleagues, Those People Are no Longer Colleagues." In Proceedings of the 39th Conference Translating and the Computer, 59-69.

[34] Lucas Nunes Vieira \& Elisa Alonso (2020) Translating perceptions and managing expectations: an analysis of management and production perspectives on machine translation, Perspectives, 28:2, 163184, DOI: 10.1080/0907676X.2019.1646776

[35] Massardo, Isabella, and Jaap van der Meer. 2017. The Translation Industry in 2022: A Report from the TAUS Industry Summit. Translation Automation User Society. Accessed December 4, 2017. https://www. taus.net/think-tank/reports/event-reports/the-translation-industry-in-2022.

[36] Milton, John, and Paul Bandia 2009. Agents of translation. Amsterdam John Benjamins.

[37] Mitchell, Christine, and Rita Raley, eds. 2018. "Translation-Machination" special issue, Amodern 8. Accessed March 27, 2018.

[38] Moorkens, Joss. 2017. “Under Pressure: Translation in Times of Austerity." Perspectives 25 (3): $464-477$. doi: 10.1080/0907676X.2017.1285331.

[39] Nida, E. A. 1964. Toward a science of translating with special reference to principles and procedures involved in bible translating. Leiden: E. J. Brill. 
[40] O'Brien, Sharon. 2006. Eye tracking and translation memory matches. Perspectives: Studies in Translatology, 14(3): 185-205.

[41] OECD. 2017. OECD Employment Outlook 2017. Paris: OECD Publishing.

[42] Olohan, Maeve. 2011. "Translators and Translation Technology: The Dance of Agency." Translation Studies 4 (3): 342-357. doi: 10.1080/14781700.2011.589656.

[43] Orlikowski, Wanda J. 2005. Material works: Exploring the situated entanglement of technological performativity and human agency. Scandinavian Journal of Information Systems, 17(1): 183-6.

[44] Paloposki, O. 2011. Domestication and foreignization. Handbook of Translation Studies, 2, 40-42.

[45] Pickering Andrew. 1995. The mangle of practice. Time, agency, and science. Chicago, IL University of Chicago Press.

[46] Pickering Andrew. 2005a. Decentering sociology: Synthetic dyes and social theory. Perspectives on Science 13, no. 3:352 - 405

[47] Pickering Andrew. 2005b. From dyes to Iraq: A reply to Jonathan Harwood. Perspectives on Science 13, no. 341625 .

[48] Pickering Andrew. 2008a. New ontologies. In The mangle in practice. Science, society and becoming Andrew Pickering and Keith Guzik Durham, NC Duke University Press 1- 14.

[49] Pickering Andrew. 2008b. Preface. In The mangle in practice. Science, society and becoming Andrew Pickering and Keith Guzik Durham, NC Duke University Press. 1 -14

[50] Pickering, Andrew. 1993. The mangle of practice: Agency and emergence in the sociology of science. The American Journal of Sociology, 99(3): 559-89.

[51] Rammert, Werner. 2008. "Where the action is: Distributed agency between humans, machines, and programs". In Paradoxes of interactivity: Perspectives for media theory, human-computer interaction, and artistic investigations, Edited by Seifert, Uwe, Hyun Kim, Jin and Moore, Anthony. Bielefeld: transcript.

[52] Stibbe, M. 2009. Translation vs. Transcreation in Bad Language: Writing, marketing and technology. Retrieved in June 2014 from http://www.badlanguage.net/translation-vs-transcreation.

[53] Venuti, L. 2008. The translator's invisibility: A history of translation. Routledge.

[54] Wolf, Michaela, and Alexandra Fukari 2007. Constructing a sociology of translation. Amsterdam John Benjamins.

\section{AUTHOR's BIOGRAPHY}

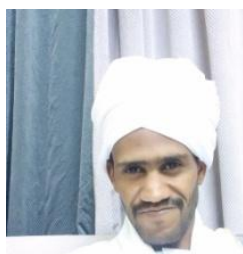

Dr. Mousab Alata ElseddigAdiel, is currently working as an Assistant Professor of Translation for Imam Abdulrahman Bin Faisal University (KSA). He previously worked as a lecturer for the College of Arts, English Language Department affiliated to Omdurman Islamic University (Sudan). Formerly he was the senior of the translators of Sudan National Audit Chamber where he translated many documents and interpreted the chamber workshops with international organizations of audit field. Also he worked as English language trainer for Ministry of Defense of the Sudan He started his career as an interpreter for Ministry of Finance, Economy and Civil Service of North Darfur State in the west of the Sudan.

Google scholar: https://scholar.google.com/citations?user=s2LH9F4AAAAJ\&hl=en

ORCID: https://orcid.org/my-orcid

Citation: Adiel, M.A. "Automatic Translation of Arabic Classic Poetry; Case-Study of Google Translate" International Journal of Humanities Social Sciences and Education (IJHSSE), vol 8, no. 8, 2021, pp.81-95. doi: https://doi.org/10.20431/2349-0381.0808007.

Copyright: (C) 2021 Authors. This is an open-access article distributed under the terms of the Creative Commons Attribution License, which permits unrestricted use, distribution, and reproduction in any medium, provided the original author and source are credited. 